\title{
XXII. Method of solving adfected quadratic equations. in a Letter to Mr. Peter Nicholson
}

\section{Mr. Joseph Seers}

To cite this article: Mr. Joseph Seers (1828) XXII. Method of solving adfected quadratic equations. in a Letter to Mr. Peter Nicholson, Philosophical Magazine Series 2, 4:20, 125-126, DOI: $10.1080 / 14786442808674742$

To link to this article: http://dx.doi.org/10.1080/14786442808674742

里 Published online: 10 Jul 2009.

Submit your article to this journal

Џll Article views: 2

Q View related articles $\square$ 
which however must be either modern or accidental, as they could hardly have withstood the waves for so many centuries.

I have nothing to add to the received opinion, that it must have been built before Roman arts and civilization (and in particular the use of mortar) travelled so far north.

Dr. Macculloch, after describing in the Geological Transactions, vol. ii. the Fort of DunMacSniochan near Oban (which I had intended to visit, but being hindered, visited this in Bute instead), combats at length and successfully the opinion, that the vitrifaction was the effect of natural causes; but $I$ think the opinion could never have been held by one who had seen this fort in Bute, where the traces of art are so evident and so undeniable.

The wall must have been first built, and then made compact and solid by vitrifaction, which must have required a considerable fire to be moved from place to place, as the work proceeded.

Samuel Sharpe.

XXII. Method of solving adfected Quadratic Equations. By $M r$. Joseph Seers ; in a Letter to Mr. Peter Nicholson*.

Dear Sir,

I BEG leave herein to submit to your inspection, \&c. the method I discovered and mentioned to you, about two months ago, of solving adfected quadratic equations. I flatter myself it is quite new; and $I$ think it inferior to none in present use. It is as follows:

Whatever be the original form of a quadratic equation, it must always be reduced to this formula of three terms; viz. $x^{2} \pm p x \pm q=0$.

In this formula, it is to be observed that $p$ is the sum of the root, and that $q$ is their product. And having their sum, and substituting $(d)$ for their difference, we have, by a well-known theorem, the two roots in this expression $\frac{\mp p \pm d}{2}$; in which expression the sign of $p$ is always contrary to what it is in the above formula. Moreover, we have, as before observed, $\frac{p+d}{2} \times \frac{p-d}{2}= \pm q$. In which equation $d= \pm$ $\sqrt{p^{2} \mp 4 q}$ : here the sign of $q$ is contrary to what it is in the formula. Hence, $\frac{\mp p \pm d}{2}=\frac{\mp p \pm \sqrt{p^{2} \mp 4 q}}{2}$ : an expression containing the two roots of the given equation in terms of known quantities.

* Communicated by Mr. P. Nicholson. 

of $x$.

Example:-Given $x^{2}-17 x+35=0 . \quad$ To find the values

Here $x=\frac{17 \pm d}{2}$. Moreover, $\frac{17+d}{2} \times \frac{17-d}{2}=35$.

Hence, $17^{2}-d^{2}=140 \ldots \ldots$ or, $d^{2}=149$.

$$
\therefore d= \pm \sqrt{149}= \pm 12.206+\& \mathrm{c} \text {. }
$$

$\therefore x=(17+12.206+8 \mathrm{c}$. $) \div 2$. Or, $(17-12.206+\& \mathrm{c}$. $) \div 2$. $=14.603+\& \mathrm{c}$., or $2.397+\& \mathrm{c}$.

I will not trouble you with any more examples, as there is no need. I remain, Dear Sir,

Chelsea, June $20,1828$.

Your most obedient and much obliged servant, Joseph Seers.

XXIII. Improved Eudiometrical Apparatus. By R. HARE, M.D. Professor of Chemistry in the University of Pennsylvania*.

\section{Piston Valve Volumeter.}

I HAVE contrived some instruments for taking volumes of gas at one time, precisely equal to those taken at another time. I call them volumeters, to avoid circumlocution. They are of two kinds, one calculated to be introduced into a bell glass, over water, or mercury; the other may be filled through an orifice, as is usual in the case of filling a common bottle over the pneumatic cistern. The annexed figure will convey a due conception of one of them, which having a piston, I call the piston valve volumeter.

The lever $\mathrm{L}$ is attached by a hinge to a piston $p$, which works inside of a chamber $\mathrm{C}$. The rod of this piston extends beyond the packing through the axis of the bulb $B$ to the orifice $O$ in its apex, where it sustains a valve, by which this orifice is kept close, so long as the

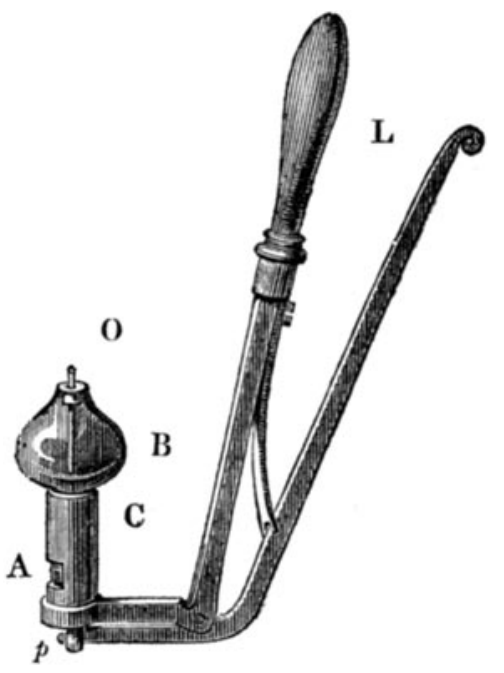

* From the American Journal of Science, with corrections and additions by the Author. 